\title{
Perceived lightness, but not brightness, of achromatic surfaces depends on perceived depth information
}

\author{
JAMES SCHIRILLO and ADAM REEVES \\ Northeastern University, Boston, Massachusetts \\ and \\ LAWRENCE AREND \\ Eye Research Institute of the Retina Foundation, Boston, Massachusetts
}

\begin{abstract}
Three experiments were conducted in an attempt to replicate and clarify Gilchrist's $(1977,1980)$ experiments on the effects of depth information on judgments of achromatic surface color. Gilchrist found that coplanarity, and not retinal adjacency, was the dominant factor in determining achromatic color matches. Because such matches can be made on the basis of either brightness or lightness, we obtained judgments of both qualities. Stereopsis was added to enhance the perceived depth effect of Gilchrist's display, which was otherwise simulated closely on a highresolution CRT. The results for lightness followed the same pattern as those of Gilchrist, but were smaller in magnitude. This discrepancy may reflect reduced extraneous lighting effects in our displays. Our results therefore agree with related studies in suggesting that lightness matches are based on relationships among coplanar surfaces. Brightness matches, however, were not influenced by perceived depth.
\end{abstract}

Achromatic surface perception is modifiable by information specifying depth relations between adjacent surfaces (Gilchrist, 1977, 1980; Wist, 1974). Here we report a replication of Gilchrist's impressive demonstrations that large shifts in perceived lightness can be obtained by using depth information to indicate which surfaces are coplanar and which are not. Gilchrist (1977) argued that "perceived lightness might be determined primarily by ratios within perceived planes rather than by all retinal ratios regardless of perceived depth" (p. 186). We have also found this to be the case for lightness judgments, but not for brightness judgments.

Usage of the terms "lightness" and "brightness" has varied over the years. We will use them here as they have been used in other recent work on surface-color perception (Arend \& Goldstein, 1987, in press). Lightness will be used to refer to apparent reflectance, perceptions ranging from blacks through grays to whites. This agrees closely with Evans's (1974) usage. Brightness will be used to refer to perceived luminance, the "overall effective intensity of the stimuli or stimulus"' (Evans, 1974, p. 192). These are two distinct, simultaneously available dimensions of experience rather than mutually exclusive "modes" of perception.

This research was supported by AFOSR Grant F49620-83-C-0052 to L. Arend and University Research Initiative AFOSR Grant F4962087-C-001 to A. Reeves. We thank R. Goldstein for writing the experimental programs and $\mathrm{A}$. Gilchrist for providing additional background information and useful comments. Requests for reprints should be addressed to J. A. Schirillo, Department of Psychology, Northeastern University, 360 Huntington Avenue, Boston, MA 02115.
Wallach $(1948,1976)$ formulated a "ratio hypothesis" in which retinally adjacent luminance ratios determine perceived achromatic reflectance, independent of illumination level. This bears directly on the question of constancy. Wallach (1976) defined constancy as "when a perceived quality or property is in better correspondence with a property of the physical object than with the stimulus variable by which the physical property is represented"' (p. 21). His ratio rule predicts perfect lightness constancy in two-dimensional (2-D) scenes when illumination is spatially uniform and background reflectances are identical. However, in 3-D scenes, achieving constancy may be more complex than Wallach's original ratio rule might suggest. Because different depth planes may have very different illuminations (e.g., over 100 to 1; Jacobsen \& Gilchrist, 1988; McCann, 1987), retinally adjacent objects whose physical depths are different may not yield appropriate luminance ratios for constancy.

Indeed, Gogel and Mershon $(1969,1977)$ and Mershon and Gogel (1970) reexamined the classic Gelb effect, using stereoscopic information. Gelb (cited in Ellis, 1939, p. 207) had used a small white "inducing" object to change the color appearance of a disk from white to gray. Gogel and Mershon found that as depth separation increased between the disk and the inducer, the Gelb effect decreased.

Wist (1974) and Wist and Susen (1973) found that depth information could influence a form of simultaneous contrast previously thought to operate only on a retinal level. Wist (1974) had subjects view a series of papers that appeared to be adjacent when viewed monocularly. When 
the papers were viewed in this manner, "scalloping" was seen, compatible with retinal-level explanations of Mach bands involving lateral inhibition (Ratliff, 1965). However, these scallops disappeared with the addition of binocular information that generated different apparent depths for the various papers.

Gilchrist $(1977,1980)$ demonstrated that perceived judgments of achromatic surfaces depend not only on the local surround (at a retinal level), but also on information that indicates shared depth relations among the surfaces. Objects occupying a single depth plane often share an illumination source, whereas objects across depth planes are more likely to differ in illumination. Wallach had not distinguished between illumination and reflectance edges in computing his retinal ratios (Gilchrist, Delman, \& Jacobsen, 1983). Gilchrist proposed a "coplanar ratio hypothesis' to account for the dependence of a surface's lightness on the depth plane that surface is perceived to be in. He postulated that accurate lightness judgments of surface appearance can only be obtained given additional perceptual information specifying depth.

Gilchrist attempted to manipulate apparent depth while maintaining similar retinal stimulation across conditions. His subjects monocularly viewed a scaled-down model of two adjoining rooms. The closer, or "near," room was dimly lit, whereas the "far" room was much brighter. The back wall of the near room had a black patch of paper on it, whereas the back wall of the far room had a white patch and a long gray strip attached to it. Overlapping the black patch was a test patch that was attached to and sticking out of the doorway (Figures la and 1b). Gilchrist created an illusion of perceived depth (Ittelson \& Kilpatrick, 1951) by cutting off two corners of the test patch (Figure 1c). This created an interposition cue so that the test patch appeared to be on the far wall behind the white patch (Figure 1d).

The terms "near" and "far" will be used throughout this paper to refer to the perceived depth plane specified by the interposition cue. The retinal information remained identical in both the near and the far cases, with the exception of the cut corners.

Gilchrist (1977) found that when the test patch appeared coplanar (in the same plane) with the near-room black patch (Figures $1 \mathrm{a}$ and $1 \mathrm{~b}$ ), the 30:1 reflectance ratio between the two patches led his subjects to judge the test patch as white (i.e., matched to a chip of 9.0/ Munsell value). When seen in the far plane (Figure 1d), the 1:72 luminance relationship between the test patch and the white patch led Gilchrist's subjects to judge the test patch as dark gray (3.5/ Munsell value). These three retinally adjacent patches produced luminance ratios of $0.033: 1: 72$. Gilchrist proposed that the test appearance depended heavily on a strong contrast with the apparently coplanar paper, the other, noncoplanar paper having virtually no effect. Although retinal stimulation differed due to the cut corners, this factor by itself should have a small or nonexistent effect on test-patch appearance, as we argue below.

Gilchrist believed that his subjects matched only lightnesses in this experiment, because the stimuli appeared

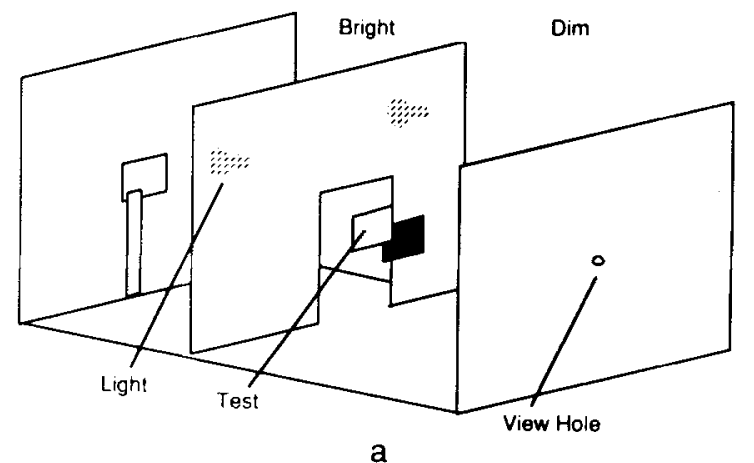

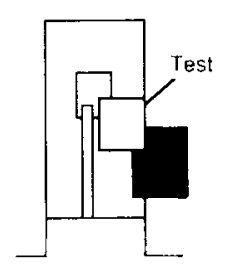

b

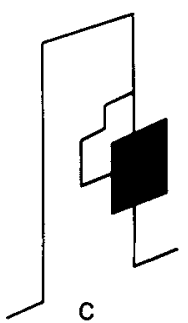

C

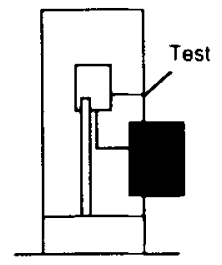

d
Figure 1. (a) Schematic diagram of Gilchrist's display. (b) Subject's view with the test in the near condition. (c) Sideview of the interposition cue manipulation, in which the actual test patch never moves. (d) Subject's view with the test in the far condition. (Artwork based on data from A. L. Gilchrist, 1977, Science, 195, pp. 185187. Copyright by the AAAS. Reprinted by permission of the publisher.)

to be object surfaces (Jacobsen \& Gilchrist, 1988). However, brightness as well as lightness matches can be obtained by having subjects view complex scenes (Arend \& Goldstein, 1987; Kozaki, 1973). Gilchrist (1980) recognized elsewhere that "ultimately, our experience of surfaces is dual; every surface is perceived at a certain lightness value as well as having a particular value of illumination"' (p. 537). However, Gilchrist (1977) did not give his subjects explicit instructions as to which attribute to judge. The present research (which includes a replication of Gilchrist, 1977) included both lightness and brightness instructions for the subjects.

\section{Lightness and Brightness Matches}

Evans (1974) noted that we simultaneously perceive several achromatic qualities in each region of a scene. For example, we see illumination as being separate from surface reflectance, and each can be distinguished from brightness. Failure to experimentally differentiate lightness from brightness matches can thus produce ambiguous data.

Arend and Goldstein (1987) demonstrated the value of obtaining lightness and brightness matches under constant illumination. They had their subjects view two complex patchworks of 32 overlapping gray surfaces, termed "Mondrians." A designated patch in the Mondrian on the right side of a display monitor could be varied in luminance to match a corresponding patch in the Mondrian on the left side. These displays were two-dimensional 
Standard

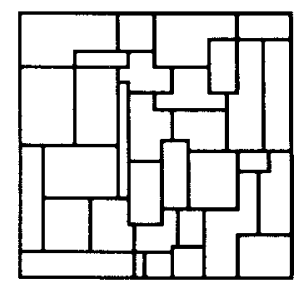

Illum Fixed
Test

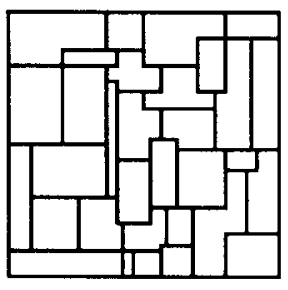

llium. varied 19:1

(1.28 log units)

Figure 2. Schematic diagram of Arend and Goldstein's simultaneous Mondrian display. Standard and test Mondrians were identical simulated reflectance arrays. Patches varied in reflectance from black $(R=0.03)$ to white $(R=0.95)$. (From "Simultaneous Constancy, Lightness, and Brightness," by $L$. E. Arend and R. Goldstein, 1987, Journal of the Optical Society of America, 4, 2281-2285. Copyright 1987 by Optical Society of America. Reprinted with permission.)

(Figure 2). The "brightness task" involved making a local match of apparent luminance between corresponding patches. The overall level of illumination of the right-hand configuration varied over a range of 19:1 (1.28 log units) among trials. Subjects' brightness matches covaried with illumination level.

A separate "lightness task" involved the same stimuli. Subjects were told to make the right-hand test patch "look as if it were cut from the same piece of paper as the left" (Appendix 1). Here, subjects' mean reflectance settings were invariant over illumination levels.

In the experiments reported below, we introduced our subjects to the lightness and brightness task by using Arend and Goldstein's (1987) patterns and procedures. Our subjects, like theirs, had little difficulty in learning the tasks.

\section{Illumination Levels and Gray Scales}

Gilchrist had produced an extreme range of luminances by using two illumination sources. The central test patch had 30 times the luminance of the "black" patch in the near room. The "white" patch in the far room was, however, 72 times the luminance of the central test patch. In the natural world, white surfaces are usually not more than 30 times as luminous as black surfaces under the same illumination. Therefore, Gilchrist's ratios exceed what is representative ecologically. Accordingly, we replicated Gilchrist's original luminance range (over 2,000:1). We also tested our subjects with a restricted range in which both coplanar contrasts were within a 30:1 ratio (giving a total luminance range of $900: 1$ ). Luminance ratios for the three main patches were set at $0.033: 1: 72$ in the $2,000: 1$ condition, and at $0.033: 1: 30$ in the $900: 1$ condition (Figure 3).

In Experiment 1, our subjects chose, from a Munsell chart, the patch that matched the test patch. Two types of Munsell charts were used: an actual paper chart (Gilchrist, 1977) and a CRT simulation of a Munsell chart (see Appendix 2). However, Jacobsen and Gilchrist (1988) recognized that Munsell charts have "been criti-

cized on the grounds that constancy results are artificially favored by the simultaneous presentation of the entire range of gray shades"' (p. 2). Because of this, our subjects in Experiment 2 adjusted the luminance of a comparison patch, surrounded by just two grays, to match the test patch.

\section{Depth Information}

Gilchrist (1977) used an interposition cue to create a perceived depth effect. Evidence from figure-ground studies has shown that interposition alone may create differences in achromatic color judgments. Coren (1969) and Fox and Patterson (1981) found that more contrast was perceived when a test area was seen as being in the foreground than when it was seen as being in the background. To determine the influence of the interposition cue by itself on the lightness effect, a control experiment was conducted. Experiment 3 used a method-ofadjustment procedure by which subjects matched the test patch when it was displayed as either foreground or background in scenes with interposition information but no disparity. All of the subjects completed Experiment 1 first. Then half of them did Experiment 2 followed by Experiment 3; the other half did Experiment 3 before doing Experiment 2 .
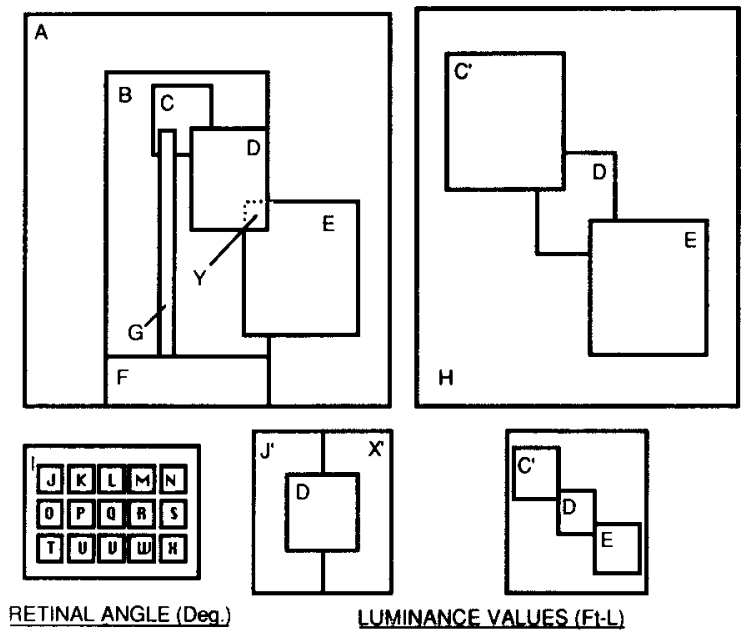

PATCH WIDTH HEIGHT

\begin{tabular}{|c|c|c|c|}
\hline \multirow{3}{*}{$\frac{\text { GlLCHRISI }}{2000: 1}$} & & & \\
\hline & \multicolumn{2}{|c|}{ REPLICATION } & \multirow{2}{*}{ INTERPOSITION } \\
\hline & $2000: 1$ & $900: 1$ & \\
\hline 1.2 & .20 & .36 & \\
\hline 8.9 & 1.50 & 1.21 & \\
\hline \multirow[t]{2}{*}{130.0} & 21.80 & 21.80 & \\
\hline & & & 3.91 \\
\hline 1.8 & .31 & .73 & 31 \\
\hline \multirow[t]{2}{*}{.06} & .01 & .02 & .13 \\
\hline & .72 & .59 & \\
\hline \multirow[t]{8}{*}{22.0} & 3.68 & 2.66 & \\
\hline & 3.05 & 3.05 & 2.62 \\
\hline & 1.69 & 1.69 & \\
\hline & 1.26 & 1.26 & \\
\hline & & 1.20 & \\
\hline & • & • & \\
\hline & .04 & .04 & \\
\hline & & .04 & \\
\hline
\end{tabular}

Figure 3. Stimulus luminance values and visual angles for all experimental conditions. 


\section{EXPERIMENT 1 FORCED-CHOICE MATCHING PROCEDURE}

\section{Method}

Subjects. Eleven undergraduate and graduate students (between 19 and 41 years of age) were paid to serve as subjects. They served as their own controls for the two depth conditions and for the lightness and brightness tasks.

Apparatus. The stimulus display was presented on a Tektronix 690SR high-resolution color monitor under the control of an Adage 3000 image processor and a VAX 11/750 minicomputer. Each area of each display was calibrated with a small-spot UDT photometer. (Further details of the apparatus, linearization, and calibration are in Arend \& Reeves, 1986, and Arend \& Goldstein, 1987). The gray-scale patterns were simulations of uniformly illuminated achromatic matte papers. Phosphor structure was invisible at the 45 -in. viewing distance.

Stereoscopic vision and simulations were used instead of the monocular vision and real rooms used by Gilchrist (1977). In Gilchrist's (1980) review of his own research, he concluded that "it is likely that these results would be produced by any method that created the same "perceived spatial arrangement" " (p. 535; see Appendix 2). The current procedure was convenient, and was compatible with the use of displays in earlier, related works (Arend \& Goldstein, 1987; Coren, 1969; Gibbs \& Lawson, 1974; Mershon \& Gogel, 1970; Wist \& Susen, 1973).

Mirrors and baffles in front of the chinrest allowed the subjects to fuse the stereoscopic pair of disparate images on the monitor. When fused, the perceived depth of the far stimulus was twice that of the near stimulus. This was calculated from angular disparities and verified by subjects' estimates.

Stimuli. Patches were $6,500^{\circ} \mathrm{K}$ (white) lights varying from 0.04 to $75 \mathrm{~cd} / \mathrm{m}^{2}$. The upper half of the monitor contained left and right images with $0.82^{\circ}$ of uncrossed disparity for the far-room patches, and $0^{\circ}$ for the near patches. The test patch had either $0^{\circ}$ or $0.82^{\circ}$ of uncrossed disparity relative to the near room, placing it in either the near or the far plane, respectively (Figure 4a). The angular sizes of all surfaces were identical to those of Gilchrist (1980; Figure 3).

Procedure. Sessions were run in the dark with only the monitor screen illuminated. Fluorescent room lights were turned on during 3-min breaks between experiments, during which time the screen was a uniform white $\left(6,500^{\circ} \mathrm{K}\right.$ at $\left.68.5 \mathrm{~cd} / \mathrm{m}^{2}\right)$. Experimental sessions lasted $1.5 \mathrm{~h}$.

The subjects practiced with the coplanar Mondrian display used by Arend and Goldstein (1987) for as long as needed (typically $15 \mathrm{~min}$ ) to learn the distinction between the lightness and brightness tasks (see Appendix 1). Practice was terminated when the subjects' responses indicated that they could easily make separate lightness and brightness matches.

The subjects then began the matching task by first using the paper Munsell chart. This was a separately illuminated white card on which a row of 15 Munsell chips was mounted, ranging in value from 2.5/ to 9.5/. The subject indicated to the experimenter the patch that most closely matched the test patch. The experimenter then uncovered the simulated Munsell chart on the lower half of the monitor screen. A second set of measurements was made with the subject choosing from the simulated chart. Like the paper chart, it contained the same gray scale of 15 patches on a flat, white background, but arranged in three rows of five (Figure $4 \mathrm{~b}$ ). ${ }^{1}$

Task. The subjects were asked to select a patch from the gray scale on the lower half of the screen that matched the designated test patch on the upper half, under either lightness or brightness instructions.

Design. Each subject received one trial in each condition. Thus, there were 11 matches for each of the four conditions ( 2 tasks $x$ 2 depths), which were administered in pseudorandom order.

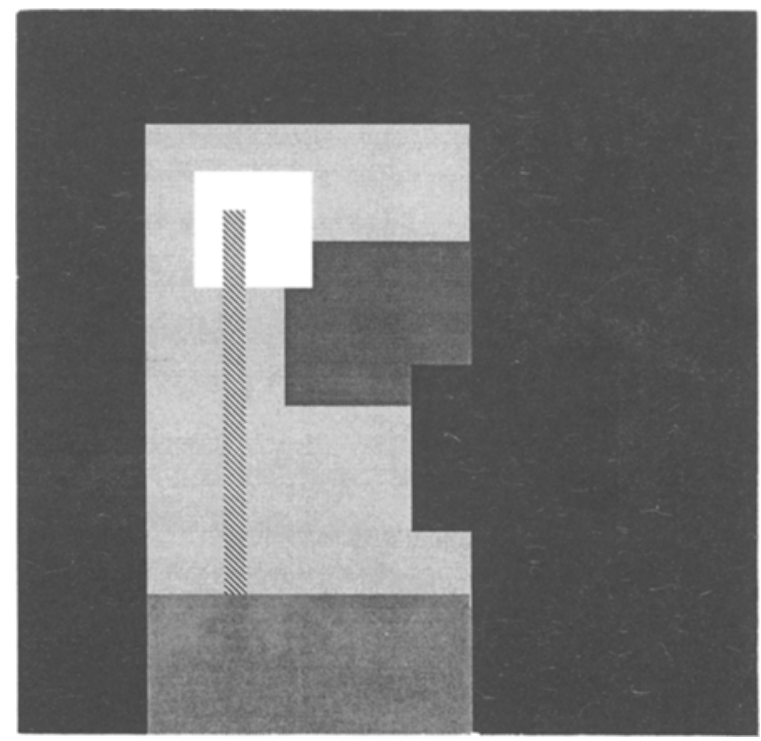

A

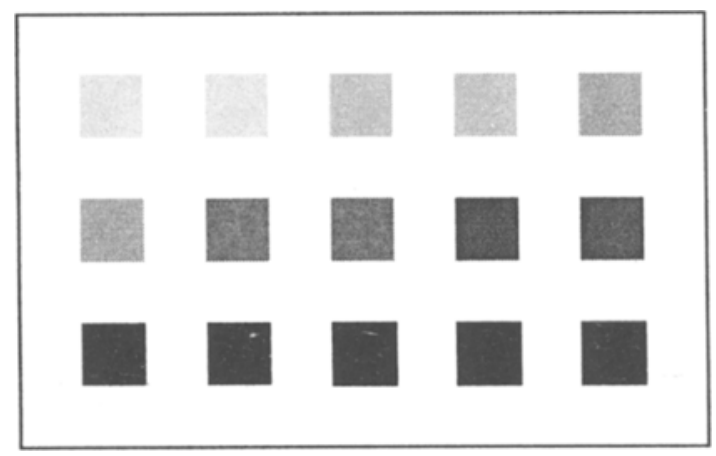

B

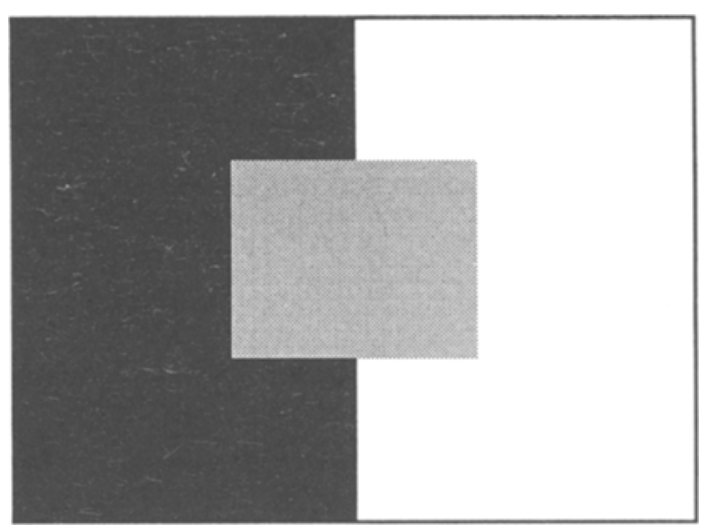

C

Figure 4. (a) Two-dimensional representation of a 3-D image presented on the top half of the display screen. (b) Fifteen-alternative forced-choice (coplanar) image presented on the bottom half of the display screen. (c) Method-of-adjustment (coplanar) image, in which the central patch could be varied in simulated reflectance from black to white. This image was presented on the bottom half of the display screen. 


\section{Results}

Lightness data for the $900: 1$ and 2,000: 1 luminance ratios under the near and far depth conditions are shown in Figure 5. Only the screen-display simulation results will be reported, since matches with the actual Munsell cards produced the same magnitude and direction of results. The test patch was judged significantly lighter in the near than in the far condition for both luminance ratios $[F(1,10)=$ $96.81, p<.01]$. There was also a significant interaction between luminance ratios and depth information $[F(2,40)$ $=27.12, p<.01]$. The difference between the near and far conditions in the 2,000:1 condition was slightly greater than that in the $900: 1$ condition (Tukey $H S D=1.63$, $p<.01$; Keppel, 1973, p. 138). However, since both ratio conditions showed the same trend, only the results for the more ecologically valid 900:1 luminance ratio are reported here in detail.

Figure 6 shows lightness and brightness data under the near and far depth conditions. Lightness matches differed across depth planes (Tukey $H S D=3.25, p<.01$ ). Brightness matches, however, were not statistically different across depth planes (Tukey $H S D=0.74, p>.05$ ). This pattern held for each of the 11 subjects.

\section{EXPERIMENT 2 METHOD OF ADJUSTMENT PROCEDURE}

\section{Method}

Subjects and Apparatus. The same 11 subjects and apparatus were employed as in Experiment 1.

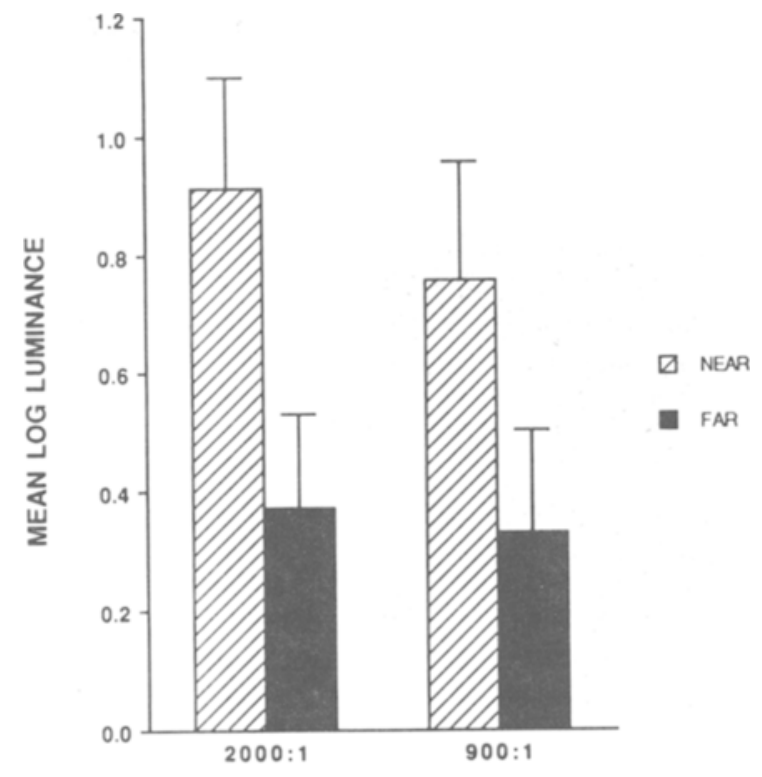

LUMINANCE RATIOS

Figure 5. Comparison of the effect of luminance ratios on lightness matches for two perceived depths with the forced-choice procedure using a 15-patch screen display. Error bars show \pm 1 SEM $(n=11)$.

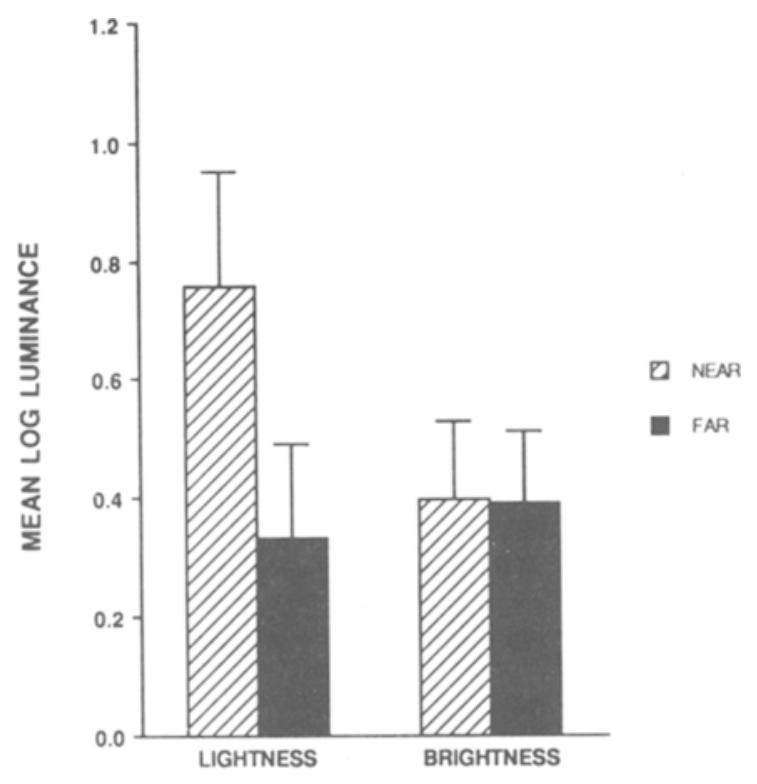

SURFACE COLOR JUDGMENT

Figure 6. Comparison of the effect of perceived depth on surface color judgment in the 900:1 luminance ratio display with the forcedchoice procedure using a 15-patch screen display. Error bars show $\pm 1 S E M(n=11)$.

Stimuli. The upper half of the display was the same as in Experiment 1. The simulated Munsell scale in the lower half of the display was replaced by a variable-luminance patch centered on a 30:1 bisected background (Figure 4c). The black-white background served as an anchor for the lightness task.

Procedure. The subjects controlled the luminance of the comparison patch by moving a hand-held cursor horizontally over a high-resolution graphics tablet. The comparison patch was adjusted to match the test patch in the upper half of the display. Between trials, the computer randomly offset the horizontal position of the luminance mapping within a range of $\pm 10 \%$ to prevent position cues from influencing the matches (Figure $4 \mathrm{c}$ ). Two separate blocks of 12 matches each, one of lightness matches and another of brightness matches, were run in pseudorandom order. To decrease the likelihood that the subjects would select a match on the basis of their memory of previous comparison settings, the illumination of the bottom display was changed at random from trial to trial. Each of the four levels used $-40 \%, 60 \%, 80 \%$, or $100 \%$ of its maximal illumination $\left(75 \mathrm{~cd} / \mathrm{m}^{2}\right)$-was equally likely in a block of 12 trials. Since there were no important differences among the results obtained with the four illumination levels $[F(1,10)=1.72, p>.05]$, only the means will be reported.

Design. The subjects viewed only the $900: 1$ luminance-ratio display. They were randomly assigned to receive either the near or the far stimulus configuration first, followed by the other stimulus configuration. Counterbalanced blocks of lightness and brightness matches were obtained for each depth condition ( 2 tasks $\times 2$ depths).

\section{Results}

The method-of-adjustment procedure produced results similar to those in the forced-choice experiment. Figure 7 shows lightness and brightness data under the near and far depth conditions. Again, the test patch was judged to 
be lighter when it was in the near room than when it was in the far room (Tukey $H S D=0.24, p<.05$ ). No statistically significant difference was found between brightness matches in the two depth conditions (Tukey $H S D=0.07, p>.05$ ).

\section{EXPERIMENT 3 INTERPOSITION CUE ALONE}

Since Gilchrist used only interposition with a monocular view, the effects of interposition alone needed to be isolated in our study. This allowed us to separate out the effects of stereoscopic depth from the unavoidable addition of interposition cues.

\section{Method}

Subjects and Apparatus. The same 11 subjects and apparatus were employed as in Experiments 1 and 2.

Stimuli. Experiments 1 and 2 combined stereo and interposition information to create an effect of perceived depth. In Experiment 3, the display retained the same angular proportions as Experiments 1 and 2, but with zero depth disparity. All subjects reported that this configuration appeared as flat papers covering each other in the same depth plane (see Figure 3). The total range of luminance was 30:1, which is consistent with a black-to-white reflectance range under a single illuminant. The test patch had the same luminance value as in the $900: 1$ condition. The upper figure retained the interposition cue of the previous displays, whereas in the lower figure the patches were adjacent (Figure 8).

Procedure. The subjects adjusted the luminance of the lower comparison patch to match the test patch in either lightness or brightness. Two separate blocks of 12 matches each, one of lightness matches and another of brightness matches, were run in pseudoran-

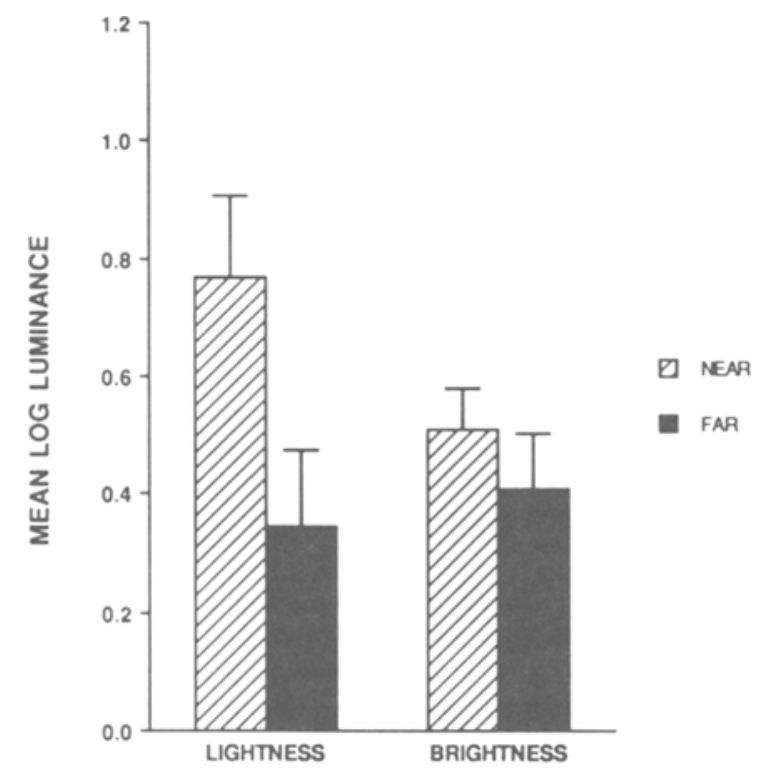

SURFACE COLOR JUDGMENT

Figure 7. Comparison of the effect of perceived depth on surface color judgment in the 900:1 luminance ratio display using the methodof-adjustment procedure. Error bars show $\pm 1 \operatorname{SEM}(n=11)$.
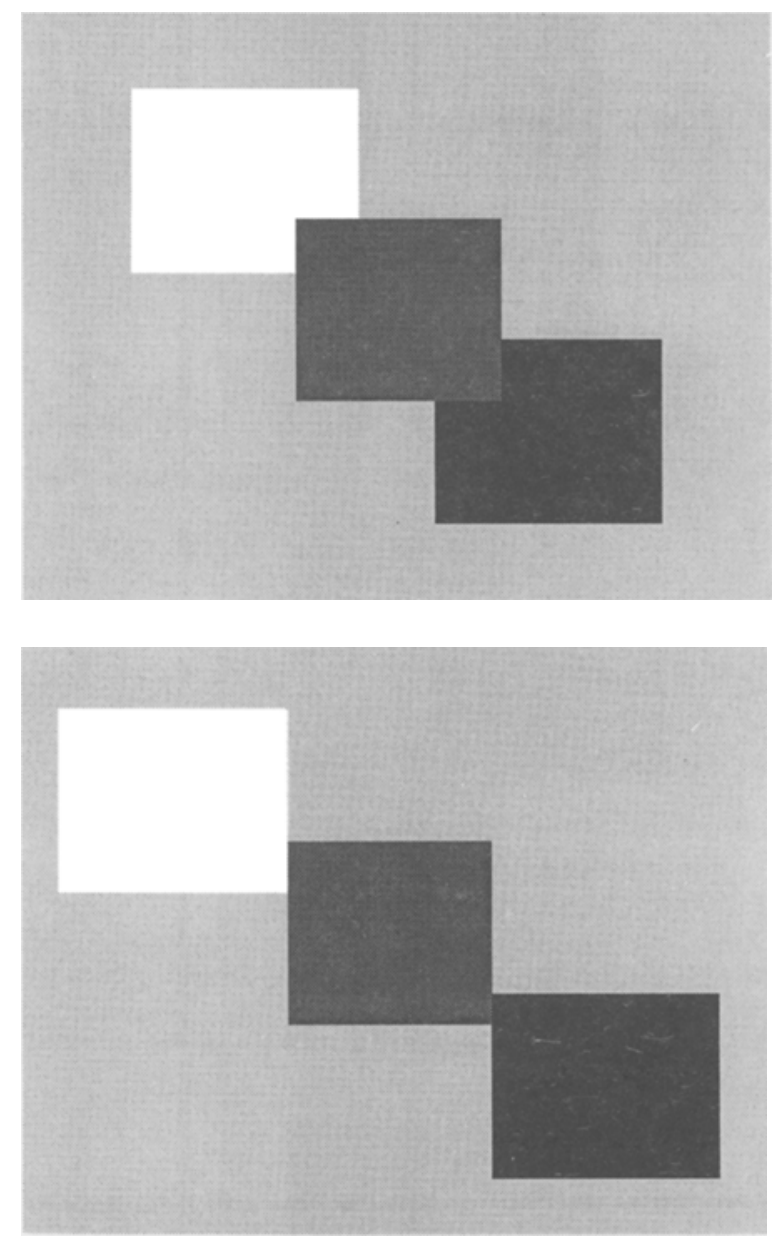

Figure 8. Diagram of the interposition cue-alone display (near condition). The central patch in the bottom half of the display could be varied in stimulus reflectance from black $(R=0.03)$ to white $(R=0.95)$.

dom order. As in Experiment 2, the bottom display appeared under $40 \%, 60 \%, 80 \%$, or $100 \%$ of its maximal illumination, with each of the four settings randomly assigned to three trials within a block.

Design. The subjects were randomly assigned to receive one of two 30:1 luminance-ratio conditions first. They all viewed the near (test patch in front) and far (test patch behind) stimulus configurations (Figure 8). Counterbalanced blocks of lightness and brightness matches were obtained using the method of adjustment.

\section{Results}

Figure 9 shows the effect of perceived depth on lightness and brightness matches using only the interposition cue to alter the test-patch appearance. The interaction between lightness and depth reported in Experiment 2 did not occur. As before, there was no interaction between brightness and depth, as can be seen in Figure 9.

\section{GENERAL DISCUSSION}

\section{Phenomenological Observations}

The subjects had no difficulties in perceiving the monitor displays in depth using stereo displays. When asked, 


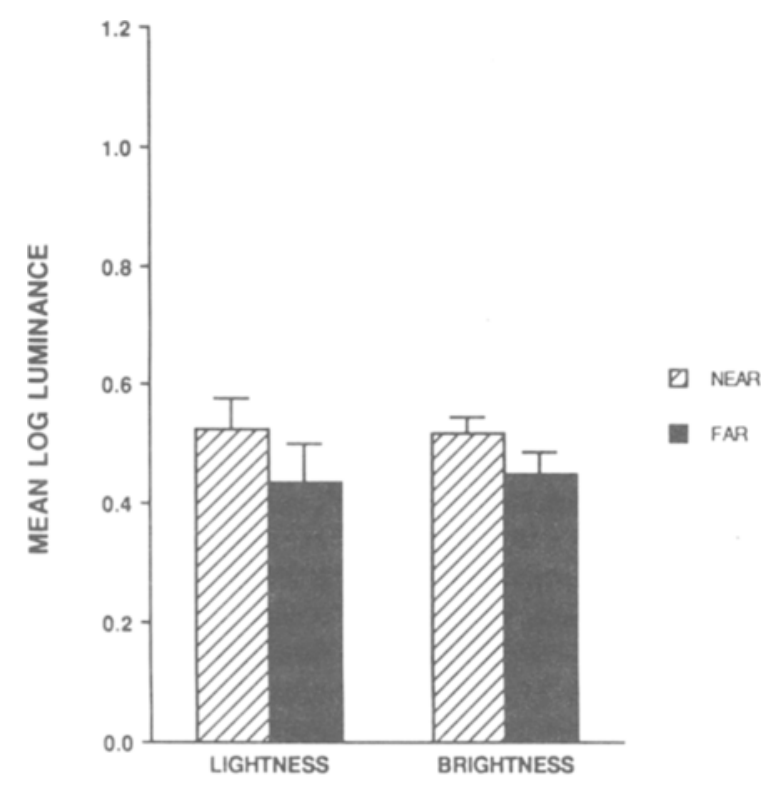

SURFACE COLOR JUDGMENT

Figure 9. Comparison of the effect of perceived depth on surface color judgment created by the interposition cue alone. Luminance ratio of the display was 30:1. Error bars show $\pm 1 S E M(n=11)$.

the subjects described the scene as "rooms in depth," and often referred to the various patches as object surfaces (e.g., "the black patch on the gray wall").

All subjects reported brightness matches as being easier than lightness matches, and felt more confident about their final settings in the case of brightness. This was reflected in slightly smaller standard errors for brightness matches than for lightness matches. In all three experiments, brightness matches also took far less time to make than did lightness matches. This was opposite to Arend and Goldstein's (1987) observations.

Our subjects were provided with both stereo and interposition information as a means of segmenting a scene into two coplanar surfaces. Depth edges are often accompanied by illumination changes in the natural environment, and our subjects' lightness responses were consistent with the notion that the depth information defined boundaries between regions under different illuminations. Brightness matches, however, were not influenced by perceived depth. Thus, our data support Gilchrist's (1977), while uncoupling the dual percepts of lightness and brightness.

\section{Illumination Levels, Gray Scales, and Depth Information}

Overall, the differences we obtained were smaller in magnitude than those of Gilchrist. Our 900:1 condition appears to represent an ecologically valid account of the magnitude of the effect of perceived depth on lightness judgments of achromatic surface color. There could be several possible sources of the discrepancy.

We can eliminate two procedural differences from the list of potential explanations. First, although our study involved a stereo manipulation to create the perceived depth effect, the lateral displacement of an image involved in creating the stereo display should not in itself have influenced the results. Mershon $(1971,1972)$ found no effect of lateral displacement in a related study of the effects of depth on lightness judgments.

Second, stimulus-area changes due to the interposition change may also have had an effect. The test square had $23 \%$ less surface area in the far condition, due to its cut corners. However, the results of Experiment 3 (Figure 9) show that this aspect of the interposition information had only a small effect on lightness and brightness matches relative to the effect of the depth information per se.

In our 900:1 lightness condition (Figure 5), the ratio of the luminance match in the near condition to that in the far condition was $2.7: 1 .^{2}$ The ratio increased to $3.5: 1$ in the 2,000:1 condition. Similarly, Gilchrist's larger ratio match of $6.6: 1$ is in part attributable to his 2,000:1 luminance ratio. Consequently, the test patch appeared to be a lighter gray in our 30:1 luminance-ratio condition than in Gilchrist's 72:1 condition.

Mershon (1972) used a 30:1 stimulus-luminance ratio in his study of depth information and lightness. The ratio of luminance matches in his data was 1.7:1. This is somewhat comparable to the 1.4:1 ratio we obtained in Experiment 3 from interposition information alone.

A second possible explanation of the larger ratio found by Gilchrist $(6.6: 1)$ may be the additional depth information due to the variations in textures and available lighting information in his experiment. Shadows and highlights may also directly contribute to lightness judgments (Emerson, 1983; Flock \& Nusinowitz, 1984; Redding \& Lester, 1980).

A number of procedural details might also have influenced the magnitude of our results. The subjects in our replication were told to shift their gaze every $1 / 2 \mathrm{sec}$ between the top depth display and the bottom flatcomparison display. All of our subjects reported that the stereo perception remained vigorous and in the correct direction throughout. However, shifting between the stimulus display and the comparison may have reduced the magnitude of contrast effects. Using stereoscopic depth information and a simultaneous center-surround display, Julesz (1971) found that simultaneous brightness contrast effects were smaller with longer exposures.

\section{Failure of Lightness Constancy}

Gilchrist's 6.6:1 ratio and our 2.7:1 ratio both fall far below the 30:1 ratio that Gilchrist's coplanar hypothesis predicts for lightness constancy within a depth plane. This may be due to the minimal number of patches in the front room. Although these two patches spanned the luminance range of physical reflectances, they may not have been 
sufficient to define a perceptual gray scale adequately. However, Arend and Goldstein (1987) obtained only somewhat better lightness constancy with a 2-D Mondrian than with a center-surround display. Further experiments, with additional patches in both depth planes, might be of value.

Another possible explanation for the failure of lightness constancy in our experiments and those of Gilchrist is that our differences exceeded the 300:1 range for human lightness constancy as often quoted and demonstrated by Arend and Goldstein (1987). However, Jacobsen and Gilchrist (1988) obtained lightness constancy over a very large luminance range $\left(10^{6}: 1\right)$.

\section{REFERENCES}

Arend, L., Goldstein, R. (1987). Simultaneous constancy, lightness and brightness. Journal of the Optical Society of America, 4, 2281-2285.

AREND, L. \& GoLDSTEIN, R. (in press). Lightness and brightness over spatial illumination gradients. Journal of the Optical Society of America.

AREND, L., \& ReEves, A. (1986). Simultaneous color constancy. Joumal of the Optical Society of America, 3, 1743-1751.

COREN, S. (1969). Brightness contrast as a function of figure-ground relations. Journal of Experimental Psychology, 80, 517-524.

ELLIS, W. D. (1939). A source book of Gestalt psychology. New York: Harcourt, Brace.

EMERSON, P. L. (1983). Cornsweet contrast, shadow, and lightness: A critique of interpretations by Redding and Lester. Perception \& Psychophysics, 33, 494-498.

Evans, R. M. (1974). The perception of color. New York: Wiley.

Flock, H. R., Nusinowitz, S. (1984). Visual structures for achro matic color perceptions. Perception \& Psychophysics, 36, 111-130.

Fox, R., \& PATTERSON, R. (1981). Depth separation and lateral interference. Perception \& Psychophysics, 30, 513-520.

GibBs, T., \& Lawson, R. B. (1974). Simultaneous brightness contrast in stereoscopic space. Vision Research, 14, 983-987.

Gilchrist, A. L. (1977). Perceived lightness depends on perceived spatial arrangement. Science, 195, 185-187.

GILCHRIST, A. L. (1980). When does perceived lightness depend on perceived spatial arrangement? Perception \& Psychophysics, 28, 527-538.

Gilchrist, A., Delman, S., \& Jacobsen, A. (1983). The classification and integration of edges as critical to the perception of reflectance and illumination. Perception \& Psychophysics, 33, 425-436.

Gogel, W. C., \& MERShon, D. H. (1969). Depth adjacency in simultaneous contrast. Perception \& Psychophysics, 5, 13-17.

Gogel, W. C., Mershon, D. H. (1977). Local autonomy in visual space. Scandinavian Journal of Psychology, 18, 237-250.

HERING, E. (1964). Outlines of a theory of the light sense. (L. M. Hurvich \& D. Jameson, Trans.). Cambridge, MA: Harvard University Press.

Ittelson, W. H., \& Kilpatrick, F. P. (1951). Experiments in perception. Scientific American, 185, 50-55.

JACOBSEN, A., GILCHRIST, A. (1988). The ratio principle holds over a million-to-one range of illumination. Perception \& Psychophysics, 43, 1-6.

JuLesz, B. (1971). Foundations of Cyclopean perception. Chicago: University of Chicago Press.

KEPPEL, G. (1973). Design and analysis: A researcher's handbook. Englewood Cliffs, NJ: Prentice-Hall.

KozaKI, A. (1973). Perception of lightness and brightness of achromatic surface color and impression of illumination. Japanese Psychological Research, 15, 194-203.

MCCANN, J. (1987, June). How is color constancy to be explained? Paper presented at the International Color Association interim meeting. Florence, Italy.
MershoN, D. H. (1971). Evidence for the relationship of depth adjacency to contrast: A response to Lie. Scandinavian Journal of Psychology, 12, 295-302.

Mershon, D. H. (1972). Relative contributions of depth and directional adjacency to simultaneous whiteness contrast. Vision Research, 12. 969-979

Mershon, D. H. , Gogel, W. C. (1970). Effects of stereoscopic cues on perceived whiteness. American Journal of Psychology, 83, 55-67.

RATLIFF, F. (1965). Mach bands: Quantitative studies on neural networks in the retina. San Francisco: Holden-Day.

Redding, G. M., Lester, C. F. (1980). Achromatic color matching as a function of apparent target orientation, target and background luminance, and lightness or brightness instructions. Perception \& Psychophysics, 27, 557-563.

WALLACH, H. (1948). Brightness constancy and the nature of achromatic colors. Journal of Experimental Psychology, 38, 310-324.

Wallach, H. (1976). On perception. New York: New York Times Book Club.

WIST, E. R. (1974). Mach bands and depth adjacency. Bulletin of the Psychonomic Society, 3, 97-99.

WIST, E. R., \& SUSEN, P. (1973). Evidence for the role of post-retinal processes in simultaneous contrast. Psychologische Forschung, 36. $1-12$.

Wyszecki, G., \& Stiles, W. S. (1982). Color science (2nd ed.). New York: Wiley.

\section{NOTES}

1. For this simulation and for comparisons with Gilchrist's data, we used the relation $V=10 Y^{1 / 2}$ between Munsell value and luminance.

2. Gilchrist (1977) used a white background for his Munsell patches (personal communication, 1987). In our replication, we also used a white background for both the paper and the screen comparison patches. The relationship between luminance and effective Munsell value is affected by background reflectance; this phenomenon has been called the "crispening effect" (Wyszecki \& Stiles, 1982, p. 499). The ratios cited here have taken this factor into account.

\section{APPENDIX 1}

\section{General Instructions to the Subjects}

"Throughout this experiment, you will be viewing either a top and bottom display presented continuously, or a top display with a paper display off to your lower right. First you will be selecting a patch from the bottom array of 15 patches to match a designated patch in the top display. Later on, you will be asked to adjust a single patch from another bottom display to match a top display. This will be done by using a mouse on the tablet in front of you to vary the intensity of the test patch. Throughout the experiment, you are to spend about the same amount of time looking at the two displays by alternating your gaze between them about once every $2 \mathrm{sec}$.

"Practice trials on how to vary the lower patch intensity by using the mouse and tablet in front of you will preface the actual data collection. You should use these trials to familiarize yourself with the appearance of varying shades of gray as they appear under several different lighting conditions.

"The remaining conditions in this experiment will be done in stereo. The mirrors in front of you will be adjusted by the experimenter until the display on the monitor is perceived in three dimensions."

\section{Brightness/Lightness Instructions for the Forced-Choice Matching Procedure}

Brightness match. "Look over the 15 patches at the bottom of the display and select one that has the same brightness as the 
designated patch in the upper display. Disregard, as much as possible, the other areas of the upper display. The patches correspond to the numbers $1 / 5$ from left to right in the top, middle, or bottom row.",

Lightness match. "Look over the 15 patches at the bottom of the display and select one that looks as if it were cut from the same piece of paper as the upper display. Utilize, as much as possible, the other areas of both displays in making your comparison. Again, the patches correspond to the numbers $1 / 5$ from left to right in the top, middle, or bottom row."

\section{Brightness/Lightness Instructions for \\ the Method-of-Adjustment and \\ Interposition Cue-Alone Procedures}

Brightness match. "Using the tablet in front of you, vary the intensity of the center gray patch until it has the same brightness as the designated patch in the display above. Disregard, as much as possible, the black-and-white background in making your comparison."

Lightness match. "Using the tablet in front of you, vary the intensity of the center gray patch until it looks as if it were cut from the same piece of paper as the designated patch in the display above. Utilize, as much as possible, the black-and-white background in making your comparison."

\section{APPENDIX 2}

\section{Real Papers and Lights Versus CRT Simulations}

In order to isolate the effective variables underlying achromatic perception, we employed idealized, simplified stimulispecifically, areas of homogenous luminance. This is the traditional, and appropriate, method of studying lightness (Evans, 1974; Hering, 1964; Wallach, 1976). It is a fundamental tenet of perceptual research that scenes producing identical retinal stimulation must be indistinguishable on any visual basis. With respect to differences between our CRT simulation (an emis- sive display) and the papers and lights being simulated (a reflective display), it is, in principle, possible to present both displays with such meticulous attention to detail that they are, in fact, indistinguishable. In practice, there are usually a number of choices to be made regarding variables thought to be unimportant to the phenomena under investigation. We must usually trust that the experimenter knew which variables were important and took care to eliminate all major artifacts.

It can be argued that the paper stimulus is more difficult to control than the CRT simulation. It is very difficult to mount papers and arrange lights so that the illumination is perfectly uniform. For example, there are often thin shadows at one or another edge of the paper patches due to overlap of the pieces of paper. In a complicated 3-D display like Gilchrist's, it is very difficult to avoid gradients of illumination on all visible surfaces. The paper display must also be viewed from a sufficient distance to eliminate all visible texture or imperfections.

With the CRT display, it is easier to eliminate artifacts, such as illumination gradients on surfaces, since they must be explicitly programmed into the display if they are desired. Therefore, CRTs can be used to meet our idealized goals. However, there are different problems with the CRT, and their relatively recent application in vision research has not yet generated widespread confidence in artifact assessment. Great care is required to avoid spatial and temporal nonuniformity of luminances due to electronic limitations of the monitor: the screen must be viewed from a great enough distance to make phosphor triads and raster lines invisible, care must be taken to mask off view of objects surrounding the monitor, and so forth.

We took all the precautions we could to eliminate such artifacts, and we are confident that no major artifacts escaped our attention.

(Manuscript received February 21, 1989; revision accepted for publication January 4, 1990.) 